\title{
A historical overview of paediatric surgery at Wits University: From embryo to adult
}

\author{
J Loveland, MB BCh, FCS (SA), Cert Paed Surg \\ Department of Paediatric Surgery, School of Clinical Medicine, Faculty of Health Sciences, University of the Witwatersrand, Johannesburg, \\ South Africa
}

Corresponding author: J Loveland (jeromeloveland@icloud.com)

\begin{abstract}
History provides wonderful insights into how society develops, providing innumerable lessons that can be used as individuals and institutions move into the future. The history of medicine provides particular value, yet it is so often overlooked by the present, society taking for granted what has often been a tremendous struggle to achieve. This overview of the history of paediatric surgery at the University of the Witwatersrand provides amazing insights into what has been achieved in a period spanning three centuries.
\end{abstract}

S Afr Med J 2020;110(8):777-782. https://doi.org/10.7196/SAMJ.2020.v110i8.14808

The Department of Paediatric Surgery, University of the Witwatersrand, has made a significant contribution to the development of paediatric surgery in South Africa and internationally, and has trained numerous paediatric surgeons who have made their mark both nationally and throughout the world. Since the recognition of paediatric surgery as an independent specialty, the department has become an established training institution for local as well as international trainees. More recently, the department has focused on enhancing its clinical research outputs, as well as developing subspecialties within the discipline. This article traces the department's origins from the infancy of surgery in Johannesburg in the 1880s to its present-day status as a large well-established department with a sound reputation for clinical service, training and research, both within South Africa and internationally.

\section{Era 1: 1886 - 1923. A broad history of surgery in Johannesburg}

The history of surgery in Johannesburg goes back to 1886, when Dr Hans Sauer performed the first adult operation ${ }^{[1,2]}$ (Fig. 1). Born in Smithfield, South Africa, in 1857 and trained in Edinburgh, Sauer was appointed by Cecil John Rhodes as Johannesburg's first district surgeon on 6 March 1887. Construction of the first hospital began in 1889 , with completion in 1890. In 1898 it was proposed that the facility be used as a teaching hospital. However, war and politics held sway, and it took a further 20 years before the foundation stone of our Medical School was laid on 28 January 1920. The University of the Witwatersrand was opened on 1 March 1922, with the Medical School one of four faculties. The first four medical students had started in 1919, and graduated in 1924. The original Medical School building was completed in $1928^{[2,3]}$ (Fig. 2).

\section{Era 2: 1923 - 1969. Transvaal Memorial Hospital for Children}

Development of children's surgery in South Africa was influenced by four stand-alone children's hospitals. The first was the Transvaal Memorial Hospital for Children (TMH), which was commissioned on 29 October 1923 in Johannesburg. The other three were the Children's Memorial Hospital, Durban (1931 - 1973), Pretoria Children's Hospital (1947 - 1987) and Red Cross War Memorial Children's Hospital (RCWMCH) in Cape Town (1956 - present).
TMH was built as a lasting monument to those who had suffered or died during World War I, and its construction was driven by

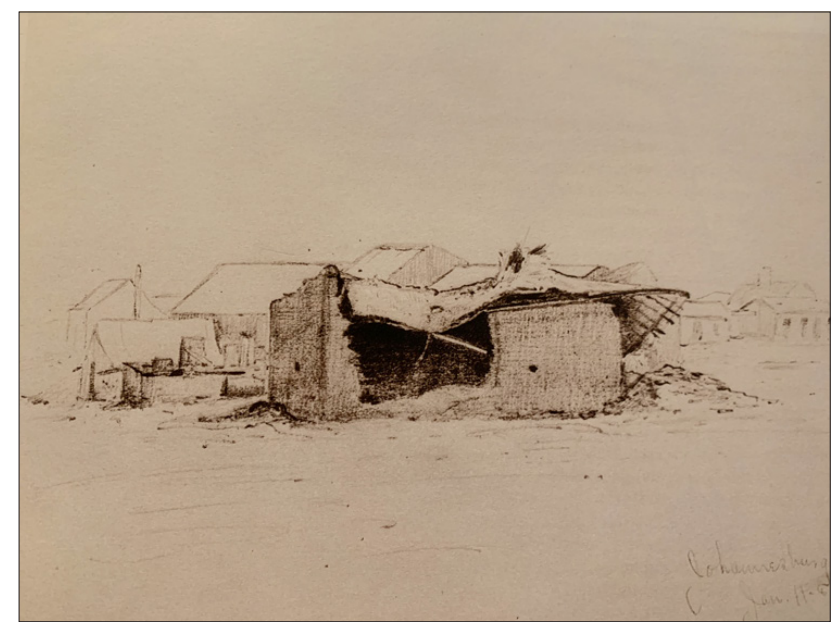

Fig. 1. The three-roomed, thatch-roofed prison in which Hans Sauer performed the first operation in Johannesburg. Pencil drawing by Ida Stone, 11 January 1888 (from Johannesburg - One Hundred Years ${ }^{[1]}$ ).

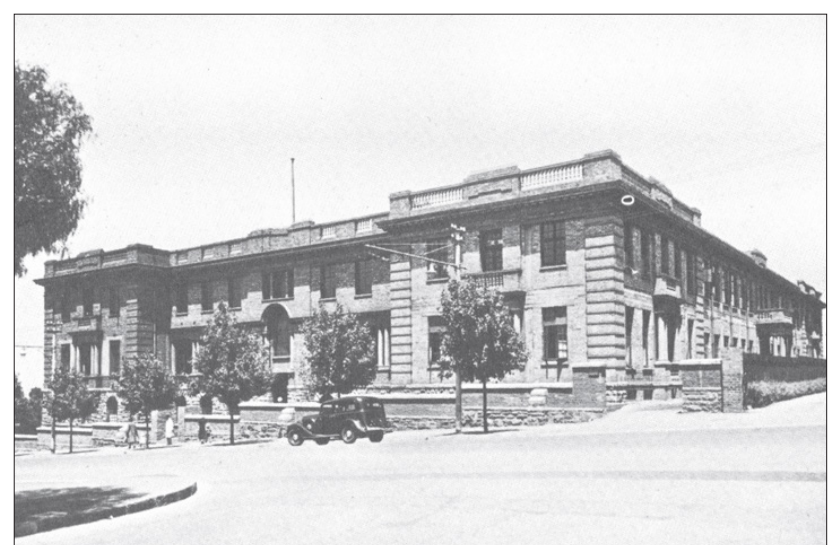

Fig. 2. Original Medical School building, Hospital Hill, Hillbrow (from The Early Years: A History of the University of the Witwatersrand, Johannesburg, and Its Precursors, $\left.1896-1939^{[3]}\right)$. 
Dr E P Baumann and the Transvaal branch of the National Council of Women ${ }^{[4]}$ (Fig. 3). It was financed by the South African Red Cross, the mining community, and public donations. The hospital had 112 beds and two operating theatres. The first admission was 7-year-old John MacFarlane, the first of untold numbers of children who would owe their health and their lives to the devoted care received in children's hospitals in South Africa. ${ }^{[4]}$

Baumann was the first appointment to $\mathrm{TMH}$, as lecturer in 'medical diseases peculiar to children'. In 1923 Dr B G Melle was appointed as part-time honorary joint medical and surgical registrar, and in the same year Mr R A Ross was appointed as 'lecturer in diseases peculiar to children and senior surgeon', with Mr J A Douglas appointed as his assistant surgeon. During these early years surgical patients were admitted under the care of paediatricians, with no independent surgical service.

In 1931 Prof. I W Brebner was appointed Chair of Surgery at Wits University, and 'diseases peculiar to children' was established as a sub-department, although under the auspices and academic responsibility of the Department of Surgery. ${ }^{[2]}$ Lee McGregor was appointed to TMH in 1932, and authored A Synopsis of Surgical Anatomy in 1936. This text was published well into the 1980s. Additional major role players included S Trubshaw, J Douglas, J Lannon and A Wolfowitz. These surgeons were the early pioneers of paediatric surgery at Wits University. In 1938 additional theatres were opened to accommodate the growing need, but the impact of fiscal constraints during and after World War II led to curtailment of the requisite development and growth. ${ }^{[4]}$

Meanwhile in 1939 in Diepkloof, Soweto, Baragwanath Hospital was conceived. General Jan Smuts, Prime Minister of South Africa, agreed to establish hospitals to treat wounded Allied soldiers. Diepkloof Farm was purchased from the Corner House Mining Group, and construction began in November 1941. ${ }^{[5]}$ The first Allied patients were admitted in March 1942, and 'Imperial Military Hospital Baragwanath' was opened on 23 September 1942. In 1947 King George VI personally visited to confer awards to the soldiers, the last of whom left the same year. The Transvaal Provincial Administration then bought the hospital for 1 million pounds. In 1948 patients and staff moved in, and the behemoth now known as 'Bara' was born (Fig. 4). The hospital changed its name to Baragwanath Hospital in 1954, in acknowledgement of John Albert Baragwanath, an immigrant

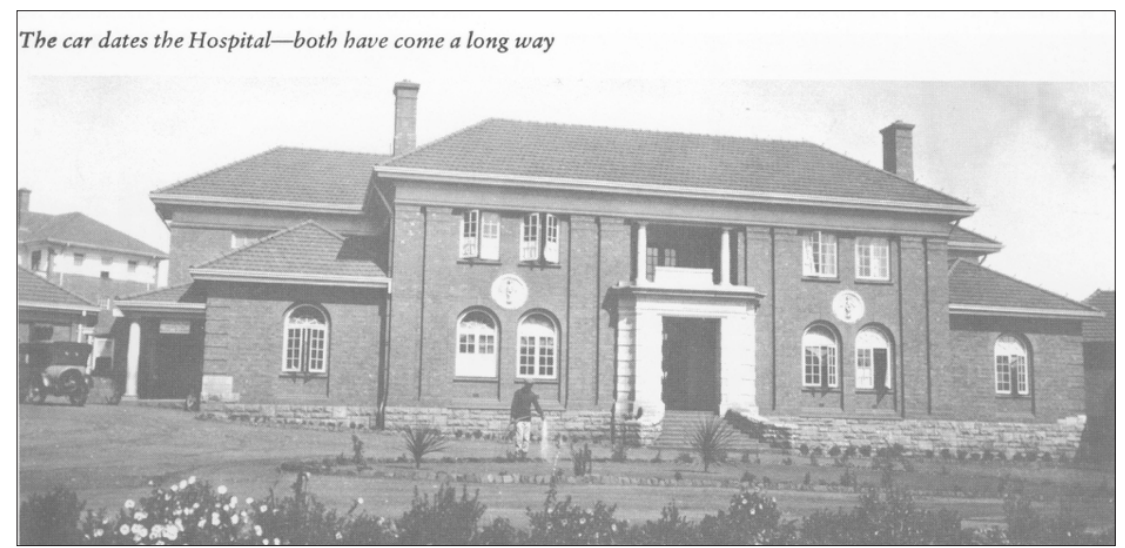

Fig. 3. Transvaal Memorial Hospital (from $50^{\text {th }}$ Anniversary Golden Book of the Transvaal Memorial Hospital for Children ${ }^{[4]}$ ).

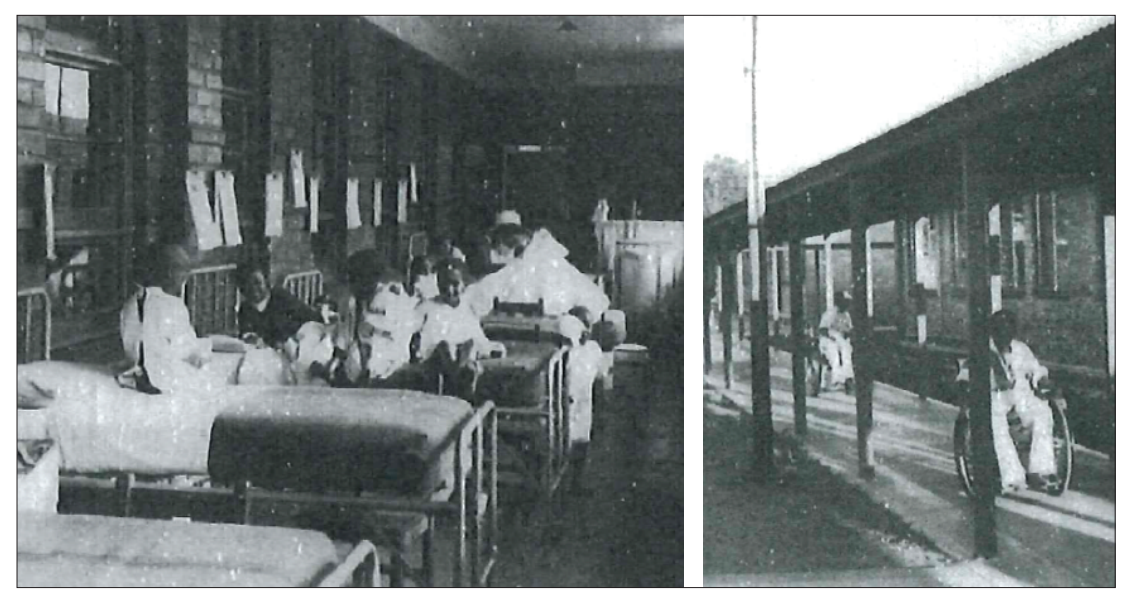

Fig. 4. Paediatric surgery 'Ward 32' (left) and adjacent corridor (right), 1955. The ward was first renovated in 2008 (from Baragwanath Hospital Yearbook, 1995).

from Cornwall, who had built the Concordia Hotel and trading post 12 miles from Johannesburg, on the road to Kimberley. ${ }^{[5]}$

In 1956 Maxie Greenberg and Michael Dinner joined the department at TMH. ${ }^{[2]}$ Jack Wolfowitz was head of surgery at TMH during this period. Even in these early days, staff had a joint responsibility to the Transvaal Provincial Administration and to Wits. In addition to Dinner, surgeons included Josh Lannon, John Beck, Lewis Spitz, P Perdicis and John Chappell. All were true experts in the broad definition of 'general' paediatric surgery. Part-time surgeons included Micky Katzen, 'Buzzy' Gampel, E Kessler, S Skapinker, H Gaylis and both Fred Kalk and William Saunders.

In 1959 a formal Department of Paediatric Surgery was established at Baragwanath Hospital. ${ }^{[6]}$ The first full-time paediatric surgical chief was appointed in 1966, this being Dr John Beck (Fig. 5). Beck, a Wits alumnus (1955), completed his paediatric surgical training at RCWMCH between 1964 and 1966 with Jannie Louw, Sid Cywes and Christiaan Barnard. In late 1966 he was invited to develop paediatric surgery in

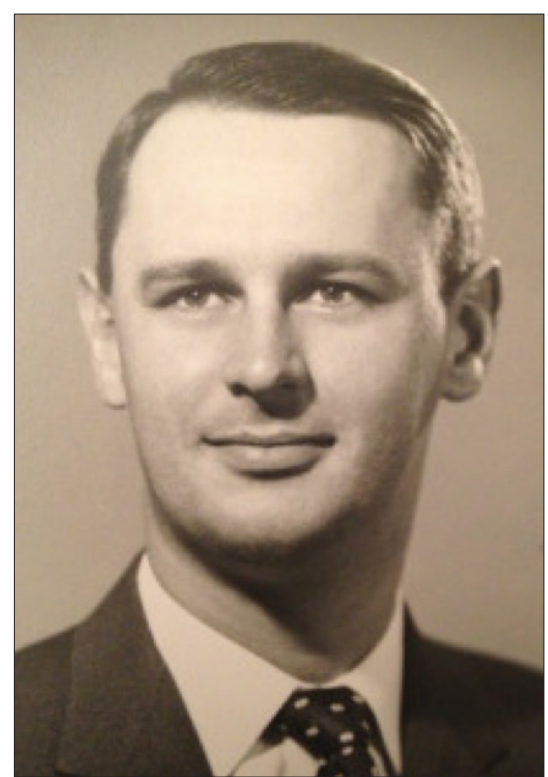

Fig. 5. Dr John Beck (from the internet).

the Transvaal with Michael Dinner. Because of apartheid, this meant working at three different institutions: TMH, Coronation Hospital and Baragwanath Hospital. Appalled, Beck moved to Leeds in 1972, 
where he was the first paediatric surgeon in Yorkshire, setting the foundations for an exceptional unit. Beck returned to South Africa after his retirement. ${ }^{[7]}$

\section{Era 3: 1969 - 1978. Prof. Michael Dinner}

Prof. D J du Plessis, Head of Surgery, recognised paediatric surgery as a formal subspecialty of general surgery in 1966, and appointed Michael Dinner as the first fulltime Chief and Academic Head in 1969. ${ }^{[8]}$ In his inaugural lecture, Dinner utilised development of the fetus and the subsequent birth and development of a child as an apt analogy for our department. ${ }^{[6]}$ This analogy was indeed a true reflection of how the departments at TMH and Baragwanath Hospital were so differently supported, with 'discrepant placental support' favouring the former in the apartheid years. Dinner defined paediatric surgeons as true 'generalists', alternatively 'experts' in the surgical care of children. His view on biliary atresia was incredibly insightful, commenting that 'outcomes of Biliary Atresia remain abject, in the best hands, with liver transplantation providing an opportunity for survival and a normal life. ${ }^{[6]}$ How right he was.

2019 marked the 50th anniversary of this momentous occasion, the formal birth of our academic department. Dinner made an enormous contribution and was promoted to associate and then full professor in 1971 and 1978, respectively. In 1970 a special edition of the South African Journal of Surgery was dedicated to paediatric surgery, and in 1974 Sid Cywes, Jannie Louw and Michael Dinner proposed the formation of the South African Association of Paediatric Surgeons (SAAPS). SAAPS was established at the Golden Jubilee Congress of the South African Medical Association on 16 July 1975, with Prof. Louw elected president (Fig. 6). The inaugural SAAPS congress took place the same year. Keynote talks were given by Dinner, on 'Idiopathic perforation of the extrahepatic bile ducts', and by the renowned Wits anatomist Prof. Phillip Tobias, on 'Man and medicine 50 years hence: A genetic prognostication.

Lewis Spitz deserves particular mention. He joined the Department of Paediatric Surgery in 1969 and in 1970 was awarded a Smith \& Nephew Fellowship and spent 6 months at Alder Hey Children's Hospital, Liverpool (with Peter Rickham), 6 months at Great Ormond Street Children's Hospital (GOS), London (with Harold Nixon), and then a further 4 months back at Alder Hey. ${ }^{[9]}$

In 1971 Spitz returned to Johannesburg and was appointed consultant at Baragwanath

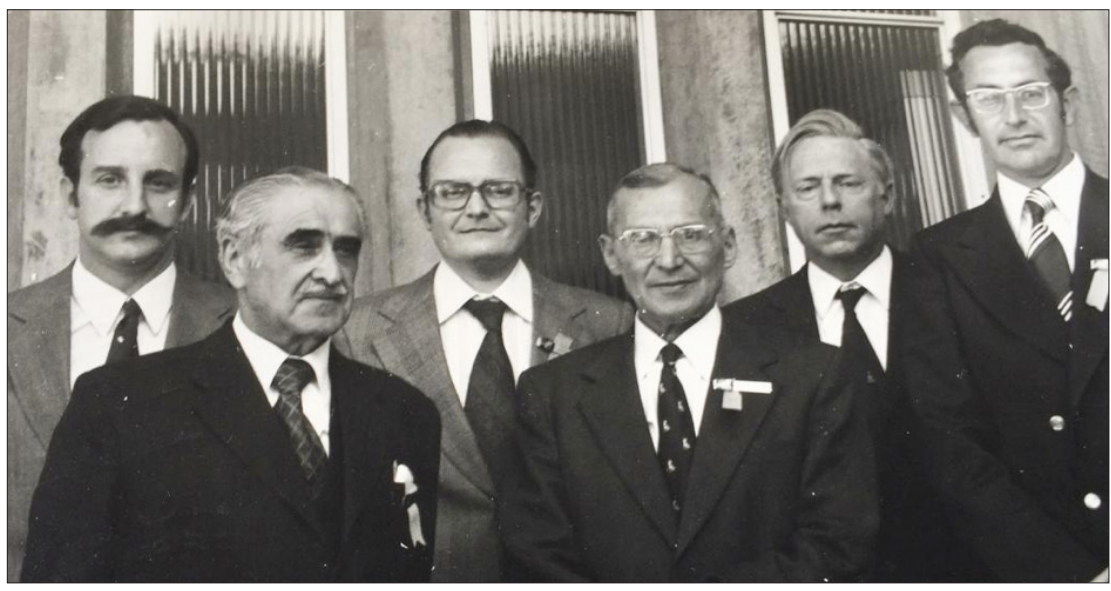

Fig. 6. Inaugural South African Association of Paediatric Surgeons Executive Committee. Left to right: Fred Kalk, Michael Dinner, Mike Davies, Jannie Louw, Bob Mickel and Sid Cywes (personal photograph, Mike Davies).

Hospital working with Beck. When Beck left in 1972, Spitz was appointed acting head until 1973 when he transferred to TMH. Sadly, Spitz accepted an appointment at the Sheffield Children's Hospital in 1974, where he worked until 1979. Lewis was then appointed to the Nuffield Professorial Chair, University of London and the Institute of Child Health, and as consultant paediatric surgeon at GOS in 1979, where he grew into an international leader in the field, working closely with Edward Kiely, who also forged his paediatric surgical practice in Johannesburg (Prof. Lewis Spitz, email correspondence May and June 2019).

Tragically, TMH was closed in 1978, as dedicated children's hospitals were considered too costly, and services were incorporated into larger facilities. Paediatrics and paediatric surgery were therefore the first specialties to move into the new Johannesburg Hospital. In comparison, RCWMCH in Cape Town only opened in 1956, but remains open and active today. In 2010 Dinner, Cywes and Bob Mickel, were recognised by the College of Paediatric Surgeons as the first professors of paediatric surgery in SA, when the aptly named 'Founders Medal' was introduced. This medal is awarded to candidates who achieve outstanding results in the final Fellowship examination.

\section{Era 4: 1978 - 1983.}

\section{Prof. John Chappell}

Dinner resigned with the closure of TMH, and university records reflect that John Chappell and Mike Davies applied for his vacant post. After a robust discussion, including how Chappell could be 'difficult', he was deemed the better candidate, and was appointed Academic Head by Prof. Bert Myburgh. Chappell was feisty and a good surgeon, and held extremely high standards when it came to patient care. His day started early, and he was well known to round at 4 am on Sundays, this to facilitate hang gliding in the Magaliesburg later in the day, a pursuit to which he lost a finger on one Saunders worked under Chappell at the new Johannesburg Hospital.

Chappell's first stroke of brilliance was during a meeting with a middle-grade English registrar, Edward Kiely (from County Cork, Ireland), at the British Association of Paediatric Surgeons meeting in Oslo in 1977 (Prof. Edward Kiely, email correspondence June 2019). Chappell suggested a job in Johannesburg. After four failed interviews for a senior registrar post in the UK, including two at GOS, Kiely accepted Chappell's offer of a senior surgeon post in Johannesburg in July 1979. Here he met a young Peter Beale, and together with Chappell they ran the unit at Johannesburg Hospital. Kiely moved from an environment where operating played second fiddle to publishing, into an environment flooded with operative exposure, this performed at an exceptional level and backed up by widely read, extremely knowledgeable surgeons. Kiely thrived in this environment, honed his clinical skills, read widely, and basked in the highveld sun. The environment under Chappell was incredibly supportive both operatively and academically, and in his own words transformed Kiely's career and life. During a visit home at the end of 1979, Kiely was asked to interview at GOS. The newly appointed professor there happened to be Spitz, who together with Chappell had trained under D J du Plessis at Wits. Kiely got the job and after 8 months in Johannesburg started work in March 1980 (Prof. Edward Kiely, email correspondence June 2019). That these two men, with such strong ties occasion. Both Peter Beale and William 
to our department, went on to contribute so enormously to paediatric surgery, growing GOS into the institution that it is today, is truly remarkable (Fig. 7)

Meanwhile, Joao da Fonseca, a Portuguese medical officer, started work at Baragwanath Hospital on 1 January 1980, and was the sole full-time employee in paediatric surgery. With an enormous clinical burden, human resources were in short supply, and consisted of one rotating general surgical registrar and one medical officer. Very little, if any, crosspollination occurred, with all academics taking place at Johannesburg Hospital. Da Fonseca went on to be the constant pillar of clinical service at Baragwanath for the next 30 years.

Era 5: 1983 - 2003.

\section{Prof. Michael Davies}

Chappell's resignation ushered in Mike Davies, who was appointed Academic Head by Prof. Bert Myburgh on 1 April 1983 and promoted to full professor 2 weeks later on 15 April (Prof. Mike Davies, personal interview 13 June 2019). A true gentleman and a master of stimulating and thoughtful discussion, Davies led the department for many formative years until his retirement in 2003. Interestingly, Mike Davies and Lewis Spitz had been classmates at Medical School.

I have struggled to get a clear view of these years, and suspect that the turbulence in South Africa at the time may well have contributed to this. The new Johannesburg Hospital provided a superb service to the white population, with Peter Beale and William Saunders working with Davies. Numerous full- and part-time surgeons, both local and international, contributed enormously to patient care at both hospitals. Names that have frequently been mentioned include Ronald Plotkin, a neurosurgeon who managed all head injuries, closed myelomeningoceles, and performed laminectomies and shunts, Micky Katzen, who ran the anorectal malformation clinic, Claude Gose and Heinz Wurtz. At Baragwanath, enormous contributions were made by foreign surgeons, notably P Erpicum, as well as L Siplovitch, J Mogilner, Z Kovacs, Bar Moar, S A-Hindi, T Goldberg and I Kawar (Prof. Mike Davies, personal interview 13 June 2019).

These were troubled years at Baragwanath Hospital, however, and from what I can determine, staffing was always at the bare minimum and in flux, with numerous international visitors and part-time staff contributing. The constant was Joao da Fonseca, a career medical officer with no formal paediatric surgical training or examinations. This single example high-
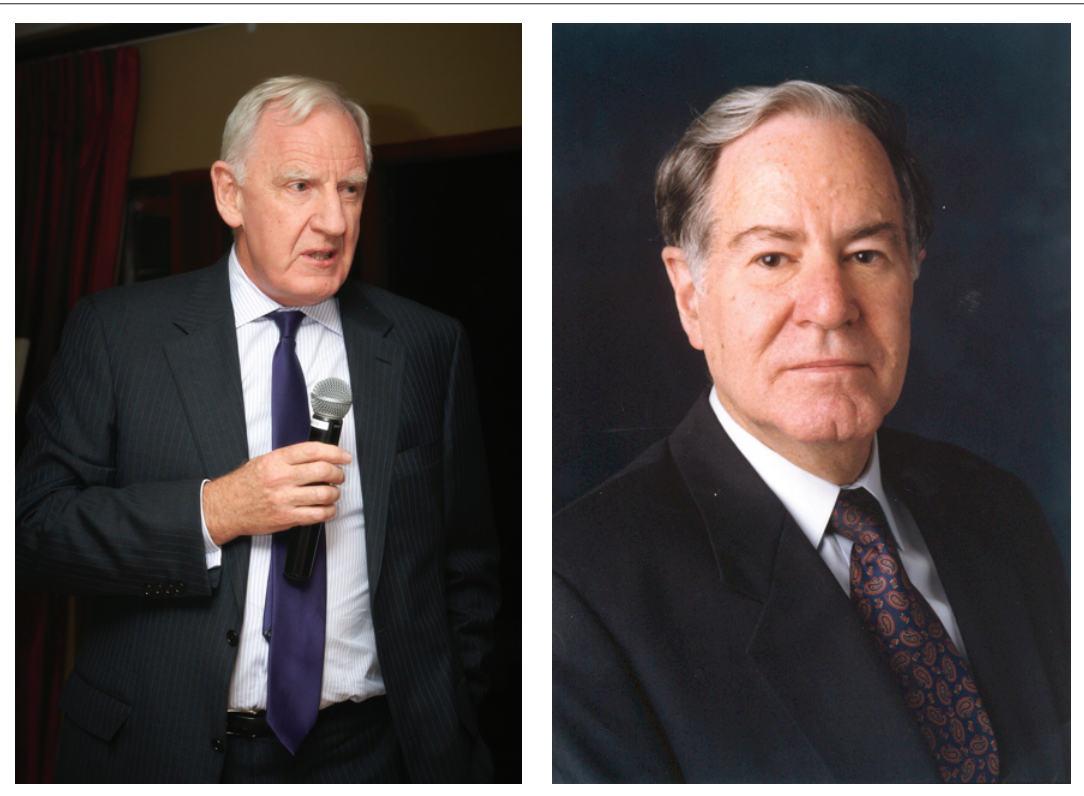

Fig. 7. Edward Kiely (left) and Lewis Spitz (right) (personally supplied).

lights the apartheid era division between Johannesburg and Baragwanath hospitals. Da Fonseca worked extremely hard to keep the ship afloat, together with Fred Kalk, and latterly William Saunders. The system was driven by clinical service, with no academia, training or administrative support. The massive workload was spread across three essentially separate units, these being the paediatric burns unit, the neonatal surgery unit, and the 'general' paediatric surgery unit, Ward 32. Nursing was excellent, and anaesthesia was driven by the renowned Dr Simon Bader.

The 1990s saw the development of a more stable staffing establishment, with Kokila Lakhoo joining da Fonseca, Kalk and Saunders. Junior staff were limited to a single rotating intern and medical officer, leaving the overall staffing desperately short to deal with the clinical workload. The only additions prior to 2006 were the allocation of a second permanent medical officer, as well as a rotating junior registrar from general surgery.

Towards the end of Davies' tenure, staff establishments at both hospitals were fairly stable, with Davies, Beale and Pitcher working at Johannesburg Hospital, and da Fonseca, Kalk, Morgan Sebele and B Baniegbhal at Baragwanath Hospital.

In 1984 the Health Professions Council of South Africa (HPCSA) registered paediatric surgery as a formal subspecialty, requiring the completion of a 2-year fellowship. It was only 18 years later in 2002 that this was structured by the Colleges of Medicine with the requirement of completing an exit exam. At Wits, this fellowship was based at Johannesburg Hospital, with no formal rotation through Baragwanath Hospital. Graduates included William Saunders, Leonie Schoeman, Graeme Pitcher, Anis Mohammed and Morgan Sebele. In the earlier years non-white doctors had no access to formal training, and we lost quality doctors from both Wits and South Africa. Mike Davies supported the unit at Baragwanath, and in the mid-1990s monthly 'grand rounds' and some academic teaching were established. Sadly, this was not universally supported.

\section{Era 6: 2003 - 2014.}

\section{Adjunct Prof. Peter Beale}

After a long career, culminating in the professorial chair of the Department of Surgery, Davies retired in 2003, whereafter Beale and Pitcher battled for the post of Academic Head. Peter Beale was appointed. Beale defined the 'general paediatric surgeon', and had a passion for operating like no other. He was mentor to many, teaching them to fear nothing. Speaking at Beale's retirement, Ed Kiely remarked that he was the best technical surgeon he had ever worked with. Again, it is remarkable that as a young scholar at Pretoria Boys' High School, Beale knew Spitz, then a medical student. They played tennis together at the Belgrade Tennis Club - apparently Beale always won!

The department at Johannesburg Hospital provided a sound clinical service, and Pitcher and Beale were promoted to adjunct professor in 2003 and 2004, respectively. Baragwanath Hospital faced an enormous workload, with da Fonseca, Kalk, Sebele and Baniegbhal performing an excellent job under trying circumstances. The unit had been neglected academically for years, on 
the basis of prejudice. There had been no recognition of training, with inadequate services and support. Yet the unit evolved under Beale, and in 2006 Pitcher was appointed Clinical Head at Baragwanath, with Jerome Loveland joining him.

The now established fellowship programme continued, with Tim Rogers, Loveland and Ellen Mapunda graduating. International fellows continued to visit the department for variable durations, with Valerio Gentilino from Genoa being the first to spend a full year of his registrar time in the department at Wits. Contributing enormously to his training, this relationship set the foundation for a sustained international collaboration. With a limited number of surgeons produced through the fellowship programme, and a desperate shortage of paediatric surgeons in SA, the HPCSA converted paediatric surgery to an independent specialty in 2007. The 4-year training programme, including primary, intermediate and final exit examinations, expanded our training platform and the two initial trainees, Andrew Grieve and Charles Carapinha, were allocated to each of the hospitals. Lesley Nunn, Derek Harrison and Theshni Govender subsequently joined.

In 2008 Pitcher resigned, leaving Loveland 'Acting Head' at Baragwanath, until formalised in 2009. Buried in clinical work, the next 2 years saw an exodus of senior surgeons, including the stalwarts da Fonseca and Kalk, Sebele, and then Gentilino (Fig. 8). 2011 saw a workforce nadir at Baragwanath. However, this was the advent of a period of enormous growth and innovation, and for the first time in many years Baragwanath grew into an environment conducive to work, including adequate office space, staff amenities and internet. The department was on the rise on all fronts, including clinical service, training, research and requisite administration. Consultant staff were attracted, including Renate Fartacek (Austria) and Chris Westgarth-Taylor (Cape Town). In addition, Ansie Welthagen was employed as an administrative and research officer, funded through the private sector.

Beale initiated significant funding campaigns, initially 'Surgikids', and then the Carte Blanche 'Making a Difference' campaign. Among other projects, these led to the first upgrade of Ward 32 at Baragwanath since the ward was built in 1942, as well as complete makeovers of the operating theatres and the neonatal surgery unit.

Clinical research was actively encouraged, particularly at Baragwanath, this aided by the initiation of an electronic records system, as well as the mandatory requirement for registrars to complete a Master of Medicine degree. Publication rates consequently started to increase. Growth in all aspects at Baragwanath Hospital, particularly research, lead to Loveland being promoted to associate professor in March 2013.

\section{Era 7: 2014 to present.}

\section{Prof. Jerome Loveland}

Beale retired in 2014 and Loveland was appointed Academic Head. It is noteworthy that for the first time in its history, the Academic Chair of Paediatric Surgery was based at Baragwanath Hospital. Ellen Mapunda was appointed acting and then permanent Clinical Head at Johannesburg Hospital in 2014 and 2016, respectively. Numerous surgeons were attracted, with Fartacek, WestgarthTaylor, Kelly Hoffman, Harrison, Grieve, Mfuneko Kopolo, Tarryn Gabler, Nirav Patel and Ronell Parkhurst working with Loveland at Baragwanath. Mapunda, Grieve, Govender and Andre Theron staffed Johannesburg Hospital. The philosophy at the hospitals differs, with Johannesburg retaining the approach of the 'general' surgeon, while Baragwanath concentrates on subspecialty development, these including burns, hepatobiliary-pancreatic, oncology, colorectal and renal.

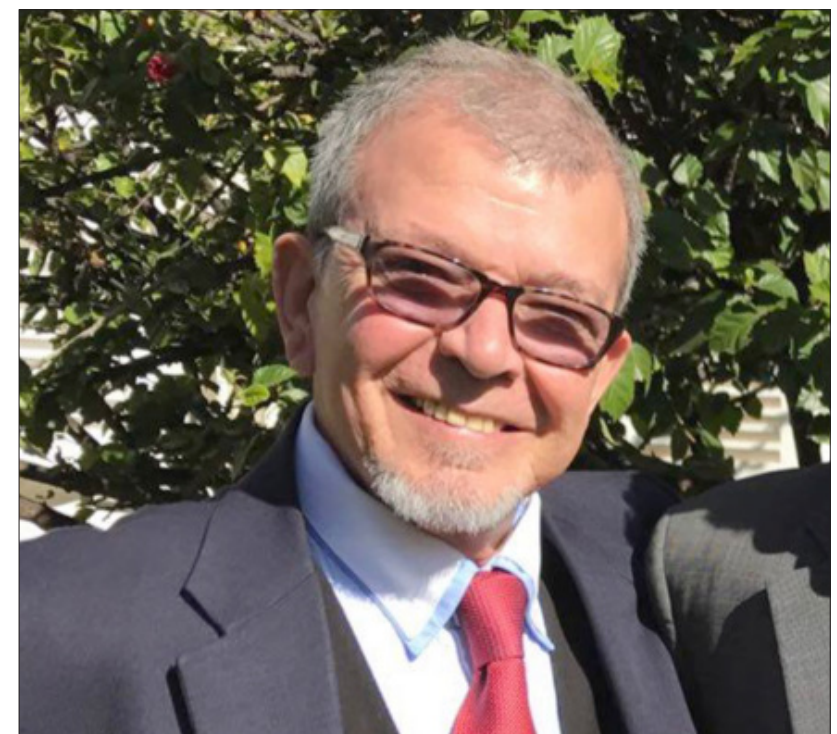

Fig. 8. Joao da Fonseca (personally supplied).

With high volumes of index pathology, excellent surgeons internationally recognised in their fields, and a well-organised training programme, the department is well suited to training of core paediatric surgical techniques and principles. This broad exposure, often lacking in high-income countries, has grown our reputation as a formidable training institution, with the goal of producing competent, if not excellent, paediatric surgeons.

The training programme has flourished, and Govender, Shalin Singh, Kopolo, Gabler, Patel and Zubrina Solomon have graduated. Registrar numbers have increased to 10 , excluding an additional 2 - 4 supernumerary trainees. Registrars are rotated through both hospitals, with exposure to all subspecialties and surgeons, ensuring broad exposure and perspectives. Importantly, trainees receive dedicated research support, and are allocated two 3-month research blocks during their training. Structured teaching includes grand rounds and tutorial-based education. Considerable time is dedicated to examination technique, with an exemplary final pass rate to date. Theshni Govender received the sought-after Founders Medal.

Supernumerary training has become well established, and we have a constant influx of international trainees on short-term attachments, these including Gentilino, Milan Gopal, Antonio di Cesare, Christina Oetzmann, Sonia Basson, Giulia Briusghelli, Andrea Zanini and Marina Andreetta. Finally, we have recently initiated long-term fellowships, and regularly support registrars from other universities in preparation for their exams.

Kiely emphasised operating over research, and our early years focused on service and training. However, audit and review are critical for self-improvement. Publishing enters one's experience into the public domain, ensuring transparency and stimulating change. Our research focus began in earnest in 2006. It was tough, lacking administrative support and putting an additional load on clinicians. Establishing a collaborative attitude, we can now demonstrate numerous examples where publication raised a flag, instituted change and improved outcomes. Research unit expansion has been interesting, with three posts created, two funded through our charity, Surgeons for Little Lives. This has significantly enabled research capacity, and we anticipate exponential growth.

With obvious limitations to funding from the Department of Health, the department established the Surgeons for Little Lives charity, focused on improving care given to children requiring surgery. Surgeons for Little Lives has raised over ZAR50 million 

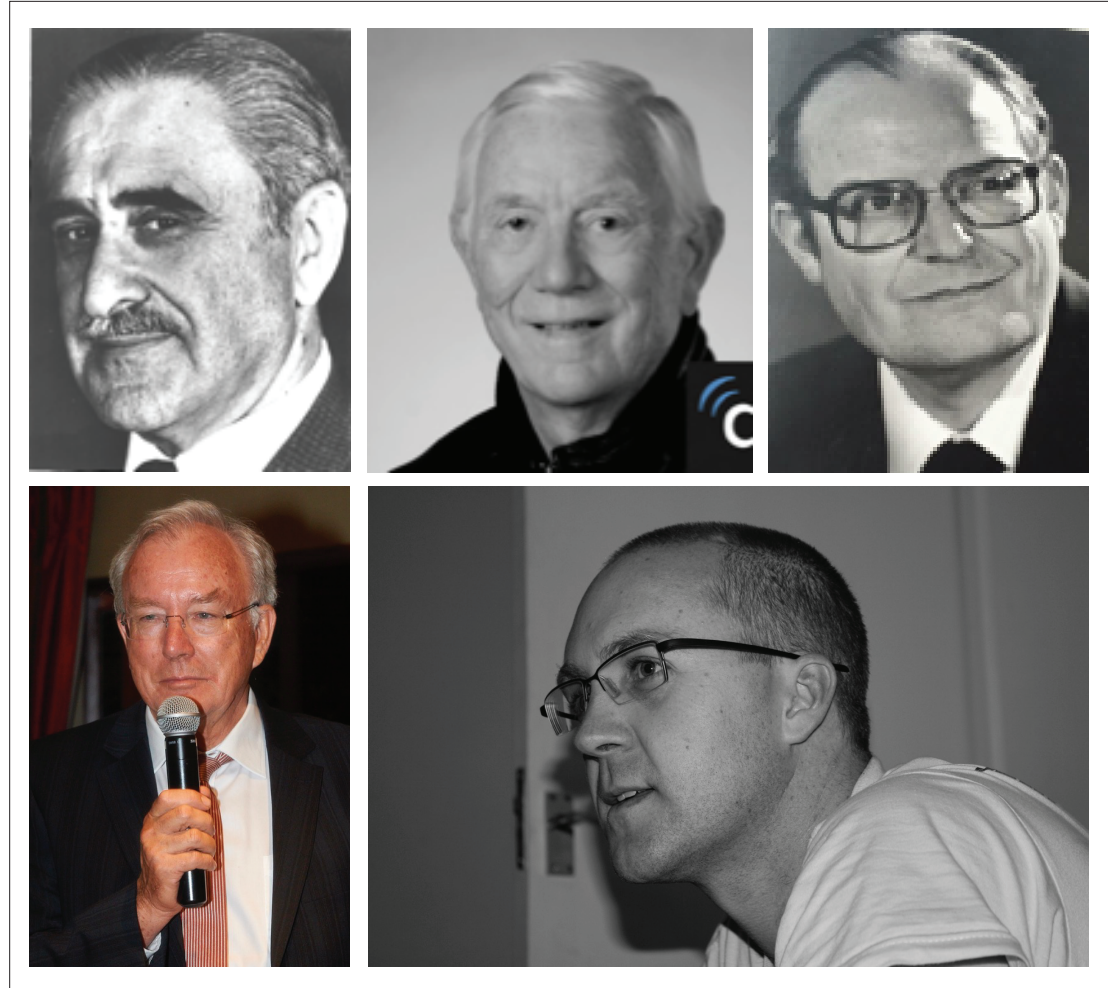

Fig. 9. Academic Chairs. Left to right, top: Michael Dinner, John Chappell and Mike Davies; bottom: Peter Beale and Jerome Loveland (various sources).

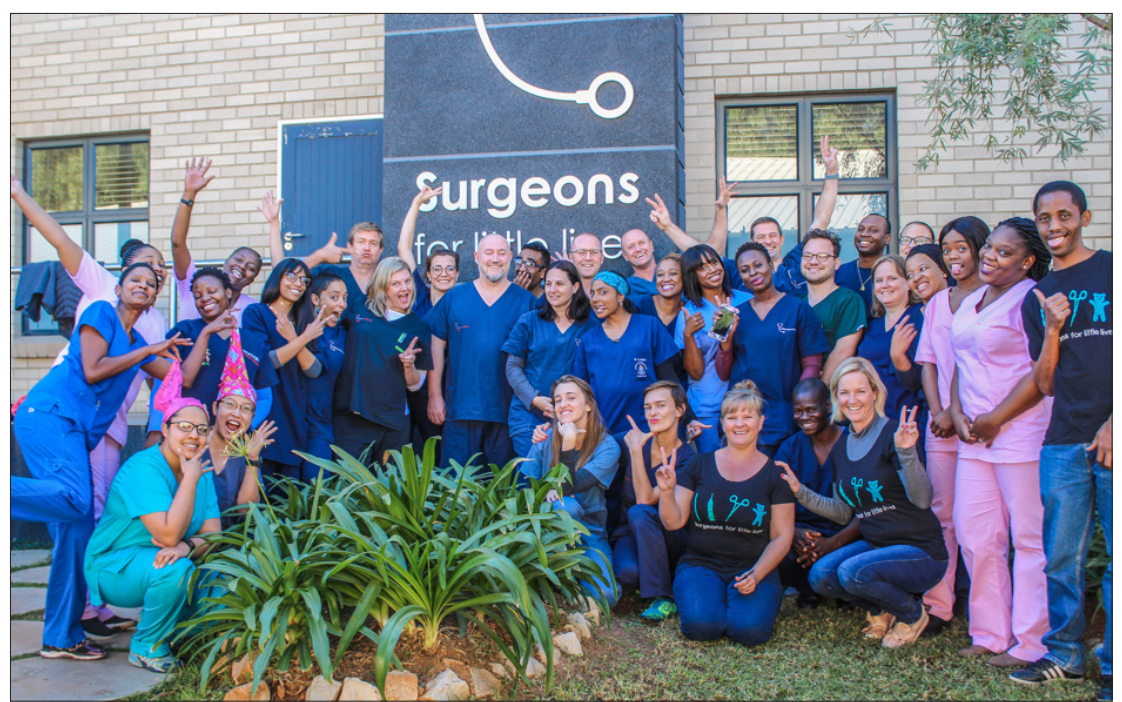

Fig. 10. The Department of Paediatric Surgery,

since its inception in 2015, directed towards numerous projects in our department. The effect has been revolutionary, highlighted by the construction of a state-of-the-art outpatient department and a 24-bed sleepover facility for parents. and the South African paediatric surgical community, Prof. Mark Davenport, King's College Hospital, London, was awarded an honorary fellowship by the College of Paediatric Surgeons of South Africa in 2019.

What a rich history this department has (Fig. 9)! It has been more than an honour to research and present our humble beginnings and development. It is most certainly a department to be exceedingly proud of. With regard to the troubled history of Baragwanath Hospital, whoever would have thought that from a nadir of four staff members in 2011, we would have built up our clinical department, established a charity, and significantly grown research, bringing a rough 'concept plan' to reality. To the entire paediatric surgical team affiliated to the University of the Witwatersrand, past and present: you can all be immensely proud of what has been achieved (Fig. 10).

My role in this paper has simply been to tell a story, and I owe an enormous debt of gratitude to those before me who have provided the history, as well as to those who have helped me compile this manuscript. Mike Davies, Ansie Welthagen, Alastair Millar, Edward Kiely, Mark Davenport, Alta Withers, Tarryn Gabler, Nirav Patel, Heinz Rode, Peter Beale, Kokila Lakhoo and Lewis Spitz, among others, have made an invaluable contribution. Thank you.

Author contributions. Sole author.

Funding. None.

Conflicts of interest. None.

\footnotetext{
1. Beattie D, Hessian B, Clarke J, et al. Johannesburg - One Hundred Years. 1st ed. Johannesburg: Chris van Rensburg Publications, October 1986

2. Veller M. Department of Surgery, University of the Witwatersrand - a brief history. S Afr J Surg 2006;44(2):42-51. 3. Murray BK. Wits - The Early Years: A History of the University of the Witwatersrand, Johannesburg, and Its Precursors, 1896 1939. Johannesburg: Wits University Press, 1982.

4. Beaconsfield M. $50^{\text {th }}$ Anniversary Golden Book of the Transvaal Memorial Hospital for Children. Northern Cape Printers, 1973 .

5. Horwitz S. Baragwanath Hospital, Soweto: A History of Horwitz S. Baragwanath Hospital, Soweto: A History of
Medical Care 1942 - 1990. Johannesburg: Wits University Medical Care 1942 - 1990. Johannesburg: Wits University
Press, 2013.

6. Dinner M. The Lifeline of the Unborn Child and Some Associated Congenital Abnormalities. Johannesburg: Wits University Press, 1976

7. British Association of Paediatric Surgeons. John Beck Obituary. https://www.baps.org.uk/news/obituary/john-beckobituary/ (accessed 30 June 2020).

8. Press Release: The Reporter. 27 January 1978
}

Accepted 21 April 2020. 